\title{
Effects of Rapid Thermal Annealing on the Structural, Electrical, and Optical Properties of Zr-Doped ZnO Thin Films Grown by Atomic Layer Deposition
}

\author{
Jingjin Wu ${ }^{1}$, Yinchao Zhao ${ }^{1}$, Ce Zhou Zhao ${ }^{2, *}$, Li Yang ${ }^{3}$, Qifeng Lu ${ }^{1}$, Qian Zhang ${ }^{3}$, \\ Jeremy Smith ${ }^{1}$ and Yongming Zhao ${ }^{4,5}$ \\ 1 Department of Electrical Engineering and Electronics, University of Liverpool, Liverpool L69 3GJ, UK; \\ Jingjin.wu@liverpool.ac.uk (J.W.); Yinchao.zhao@liverpool.ac.uk (Y.Z.); qifeng@liverpool.ac.uk (Q.L.); \\ J.S.Smith@liverpool.ac.uk (J.S.) \\ 2 Department of Electrical and Electronic Engineering, Xi'an Jiaotong-Liverpool University, \\ Suzhou 215123, China \\ 3 Department of Chemistry, Xi'an Jiaotong-Liverpool University, Suzhou 215123, China; \\ Li.Yang@xjtlu.edu.cn (L.Y.); Qian.Zhang@xjtlu.edu.cn (Q.Z.) \\ 4 Key Lab of Nanodevices and Applications, Suzhou Institute of Nano-Tech and Nano-Bionics, \\ Chinese Academy of Sciences (CAS), Suzhou 215123, China; ymzhao2009@sinano.ac.cn \\ 5 University of Chinese Academy of Sciences, Beijing 100049, China \\ * Correspondence: cezhou.zhao@xjtlu.edu.cn; Tel.: +86-512-8816-1408
}

Academic Editor: Shankar M.L. Sastry

Received: 12 June 2016; Accepted: 9 August 2016; Published: 13 August 2016

\begin{abstract}
The 4 at. \% zirconium-doped zinc oxide ( $\mathrm{ZnO} \mathrm{Zr}$ ) films grown by atomic layer deposition (ALD) were annealed at various temperatures ranging from 350 to $950{ }^{\circ} \mathrm{C}$. The structural, electrical, and optical properties of rapid thermal annealing (RTA) treated $\mathrm{ZnO}: \mathrm{Zr}$ films have been evaluated to find out the stability limit. It was found that the grain size increased at $350{ }^{\circ} \mathrm{C}$ and decreased between 350 and $850^{\circ} \mathrm{C}$, while creeping up again at $850^{\circ} \mathrm{C}$. UV-vis characterization shows that the optical band gap shifts towards larger wavelengths. The Hall measurement shows that the resistivity almost keeps constant at low annealing temperatures, and increases rapidly after treatment at $750{ }^{\circ} \mathrm{C}$ due to the effect of both the carrier concentration and the Hall mobility. The best annealing temperature is found in the range of $350-550^{\circ} \mathrm{C}$. The $\mathrm{ZnO}: \mathrm{Zr}$ film-coated glass substrates show good optical and electrical performance up to $550{ }^{\circ} \mathrm{C}$ during superstrate thin film solar cell deposition.
\end{abstract}

Keywords: Zr-doped ZnO; atomic layer deposition; rapid thermal annealing; red-shift

\section{Introduction}

$\mathrm{ZnO}$ is believed to be a promising indium tin oxide (ITO) substitute material due to its abundance and large optical band gap, and because it can easily be doped to degeneracy. The high carrier density in the impurity-doped $\mathrm{ZnO}$ film will slightly increase the band gap due to the Burstein-Moss effect [1]. N-type dopants that are commonly used in $\mathrm{ZnO}$ are $\mathrm{Al}$ [2-4] and $\mathrm{Ga}$ [5-8], while trials on B [9,10], In [11,12], Ge [13], Ti [14], Zr [15-26], and Hf [27] are also reported. Zirconium ion dopant attracts worldwide attention due to its physical nature. The ionic size of $\mathrm{Zr}^{4+}$ is comparable to that of $\mathrm{Zn}^{2+}$ which helps to minimize the lattice distortion [25]. Moreover, zirconium-doped zinc oxide ( $\mathrm{ZnO}: \mathrm{Zr})$ films are stable at high temperature $(<800 \mathrm{~K})$ compare to ITO $(<420 \mathrm{~K})$ [28]. Stability at a high temperature is crucial for electronic device fabrication, especially for the fabrication of thin film solar cells in superstrate configuration.

Various technologies have been used to dope $\mathrm{Zr}$ on $\mathrm{ZnO}$, including magnetron sputtering [15-17], spray pyrolysis [19,20], sol-gel [23], pulsed laser deposition [21,22], and atomic layer deposition 
(ALD) $[24,25]$. ALD was introduced in ZnO:Zr thin films' deposition due to its ability to accurate control the thin film composition and thickness. In principle, ALD proceeds in layer-by-layer growth, hence the doping concentration can be controlled by the proportion of dopant and bulk layer.

Recently, comprehensive reports about ALD-derived $\mathrm{ZnO}: \mathrm{Zr}$ thin film were presented. Lin et al. [24] first demonstrated $\mathrm{ZnO}: \mathrm{Zr}$ films by ALD. By varying the doping concentration, they obtained films with low resistivity $\left(1.3 \times 10^{-3} \mathrm{ohm} \cdot \mathrm{cm}\right)$, high carrier concentration $\left(2.2 \times 10^{20} \mathrm{~cm}^{-3}\right)$, and high transparency $(92 \%)$ in the visible spectrum [24]. Following on their research, Herodotou et al. [25] have further investigated the effects of doping concentration and thin film thickness on $\mathrm{ZnO}: \mathrm{Zr}$ films and obtained similar results. They illustrated that $\mathrm{ZnO}: \mathrm{Zr}$ film with 4.8 at. \% doping results in reduced resistivity $\left(1.44 \times 10^{-3} \mathrm{ohm} \cdot \mathrm{cm}\right)$, increased carrier density $\left(3.81 \times 10^{20} \mathrm{~cm}^{-3}\right)$, and increased optical band gap to $3.5 \mathrm{eV}$ [25]. Both of them examined the effect of doping concentration, however, the investigation of the rapid thermal annealing (RTA) process on ALD-derived $\mathrm{ZnO}: \mathrm{Zr}$ film is lacking. It is known that the stability of transparent conducting oxide (TCO) films is of great importance since TCO-coated glass will be used as the substrate in superstrate thin film solar cells and will suffer high temperature during solar cell fabrication. $\mathrm{ZnO}: \mathrm{Zr}$ film is predicted as the most likely substrate candidate in thin film solar cell fabrication. Therefore, robust and good performance of $\mathrm{ZnO}: \mathrm{Zr}$ film withstanding high temperature is of major strategic importance for solar cells fabrication. In this work, $\mathrm{ZnO}$ : Zr films with 4 at. \% doping were deposited by ALD, then the samples were subjected to RTA for $3 \mathrm{~min}$. The structural, optical, and electrical characterizations were performed to obtain a better understanding of the stability of $\mathrm{ZnO}: \mathrm{Zr}$ film under various temperatures.

\section{Results and Discussion}

\subsection{Structural Properties}

The structural properties of the annealed $\mathrm{ZnO}: \mathrm{Zr}$ films were investigated by $\mathrm{X}$-ray diffraction (XRD). Figure 1 shows the XRD patterns of the as-deposited film and films annealed at various temperatures. As shown in Figure 1, the as-grown $\mathrm{ZnO}: \mathrm{Zr}$ film is of polycrystalline structure and belongs to the hexagonal wurtzite structure. No other oxides were detected, suggesting that $\mathrm{Zr}^{4+}$ either replaced $\mathrm{Zn}^{2+}$ site, occupied at the interstitial site in the hexagonal lattice structure, or that amorphous $\mathrm{ZrO}_{2}$ phases were formed at the non-crystalline region in the grain boundary. It also indicated that the replacement and occupation of $\mathrm{Zr}^{4+}$ does not change the hexagonal wurtzite structure of the $\mathrm{ZnO}$ film. Additionally, unlike doped $\mathrm{ZnO}$ films deposited by other techniques, the $\mathrm{ZnO} \mathrm{Zr}$ films grown by ALD exhibit three diffraction peaks which correspond to the $\mathrm{ZnO}(100),(002)$, and (101) peaks. The prominent (100) diffraction peak in our work agreed with the result reported by Pung et al. [29]. They found that the intensity of the (100) peak is dominant for undoped $\mathrm{ZnO}$ films when depositing in the temperature range of $155-200{ }^{\circ} \mathrm{C}$ by ALD. This can be explained by the fact that while $\mathrm{ZnO}$ films grown using other techniques have the fastest growth rate along the c-axis [20,21], $\mathrm{ZnO}: \mathrm{Zr}$ films grown by ALD exhibit a small tensile component parallel to the c-axis instead. The lattice constants were calculated to further understand the effect of the deposition technique on the thin film structural properties. The lattice constants a and c can be obtained for the symmetric (100) and (002) planes by the formula [28]:

$$
\frac{1}{d^{2}}=\frac{4}{3}\left(\frac{h^{2}+h k+k^{2}}{a^{2}}\right)+\frac{l^{2}}{c^{2}}
$$

where $d$ is the interplanar spacing and $h, k$, and $l$ are crystal orientations. 


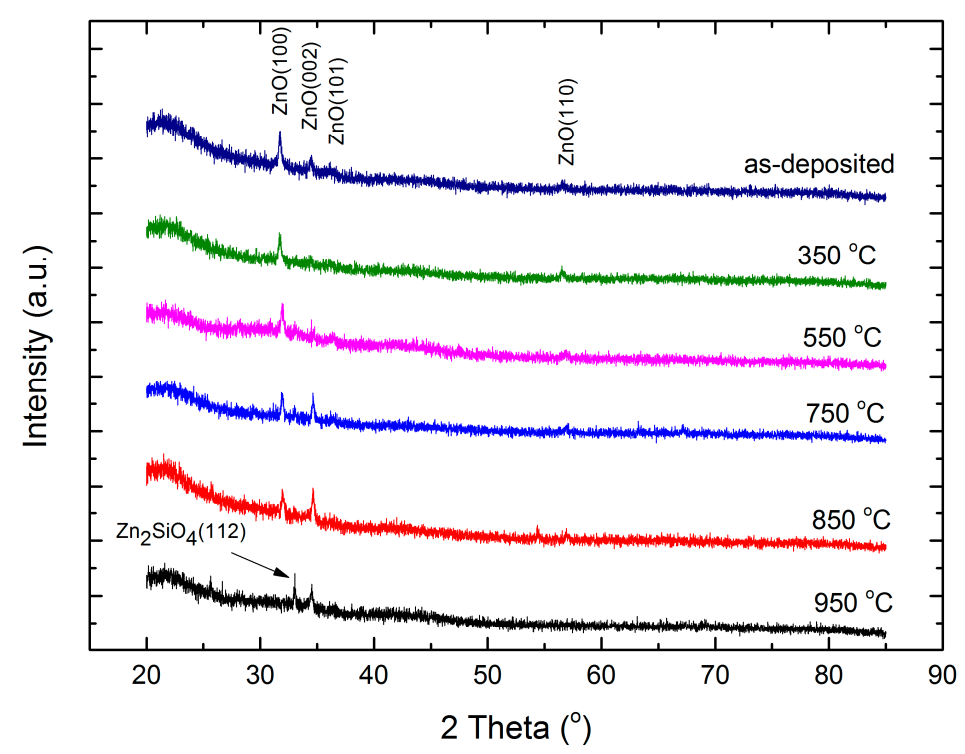

Figure 1. X-ray diffraction (XRD) pattern of $\mathrm{ZnO}: \mathrm{Zr}$ thin films annealed at different temperatures.

By calculating the c-axis lattice parameter from the XRD (002) plane, it was found that the lattice parameter for the $\mathrm{ZnO}$ films in our work is $5.19 \AA$, which is smaller than relaxed bulk $\mathrm{ZnO}(\mathrm{c}=5.207 \AA)$ and sputtered $\mathrm{ZnO}$ films (c = 5.216 $\AA$ ), as shown in Figure 2 [27]. Since the radius of $\mathrm{Zr}^{4+}(0.59 \AA)$ is similar to that of $\mathrm{Zn}^{2+}(0.6 \AA)$, the variation of lattice constants cannot be explained by the difference between the radii. This may be due to the low tensile strain paralleled to the c-axis during thin film deposition.

All three primary diffraction peaks, namely (100), (002), and (101) were still dominant when increasing the temperature up to $750^{\circ} \mathrm{C}$, which implies that all the films appear to crystallize equiaxially. When the temperature was further increase to $850{ }^{\circ} \mathrm{C}$, the (101) peak disappeared. At $950{ }^{\circ} \mathrm{C}$, the (100) and (002) peaks were no longer observed and the $\mathrm{Zn}_{2} \mathrm{SiO}_{4}$ characteristic peak at $33.027^{\circ}$ appeared in the diffraction pattern.

The grain size (D) of the corresponding films can be calculated from the full-width at half-maximum (FWHM) of the (100) peak by Scherrer's equation [27]:

$$
\mathrm{D}=\frac{k \lambda}{\beta \cos \theta}
$$

where $\lambda$ is the $X$-ray wavelength of the $\mathrm{CuK} \alpha, \theta$ is the Bragg diffraction angle, and $\beta$ is the FWHM of the (100) peak in radians. As seen in Figure 2a, the grain size increased and reached a peak value at RTA $350{ }^{\circ} \mathrm{C}$, then decreased to a minimum of $70 \mathrm{~nm}$ at $750{ }^{\circ} \mathrm{C}$. At higher temperatures of $850{ }^{\circ} \mathrm{C}$ and $950^{\circ} \mathrm{C}$, we see the grain size increasing again. The initial increase might be due to more activation energy provided to the atoms, leading to larger grains. However, at higher temperatures, the zirconium interstitials may diffuse and segregate to the non-crystalline region in the grain boundary, which will cause crystal disorder and thus shrink the grain size. It is known that the ALD-derived $\mathrm{ZnO}: \mathrm{Zr}$ thin films are composed of multilayers of $\mathrm{ZnO}$ and one zirconium oxide layer in one supercycle. Since $\mathrm{ZrO}_{2}$ and $\mathrm{ZnO}$ have such different structures and that monoclinic/cubic/tetragonal are similarly different, the formation of $\mathrm{ZrO}_{2}$ layers will be suppressed in the hexagonal wurtzite structure $\mathrm{ZnO}$. Hence, most $\mathrm{Zr}^{4+}$ ions act as $\mathrm{Zn}^{2+}$ substitution or interstitials. With high annealing temperature, more activation energy is provided to the $\mathrm{Zr}^{4+}$ atoms, which results in a diffusion of the ions into the $\mathrm{ZnO}$ matrix and the $\mathrm{ZnO}$ grain boundary. When the annealing temperature further increases to $850{ }^{\circ} \mathrm{C}$, the grain size increases again. The main reason for the grain size growth is probably due to $\mathrm{ZnO}$ grain growth and the formation of $\mathrm{Zn}_{2} \mathrm{SiO}_{4}$. 


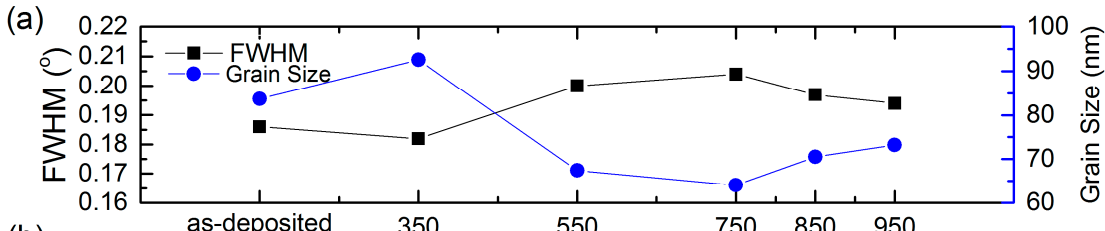

(b)

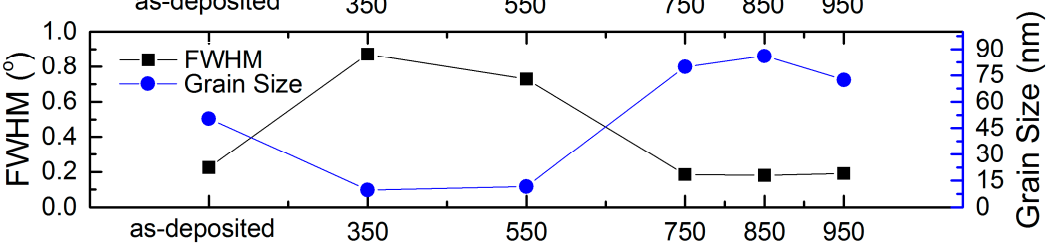

(c)

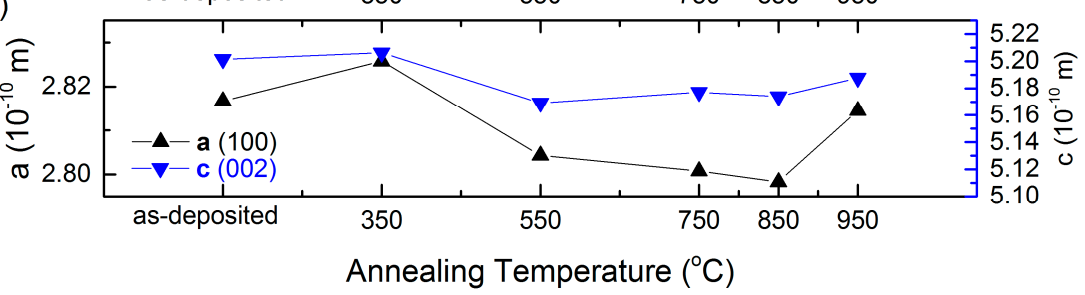

Figure 2. Variation of grain size, full-width at half-maximum (FWHM) and lattice constant with respect to annealing temperature: (a) FWHM and grain size with respect to annealing temperature for peak (100) in the XRD pattern; (b) FWHM and grain size with respect to annealing temperature for peak (002) in the XRD pattern; (c) lattice constant with respect to annealing temperature.

Since transparent conducting oxide (TCO) coated glass is used as substrate in thin film solar cell fabrication, the smoothness of the surface affects the thin films' deposition at the subsequent stage and thus device performance. Hence, it is important to study the surface morphology as a function of the annealing temperature of the $\mathrm{ZnO}: \mathrm{Zr}$ films. Figure 3 shows the atomic force microscopy (AFM) images of the as-deposited and annealed $\mathrm{ZnO}: \mathrm{Zr}$ films on a scanning area of $1 \mu \mathrm{m} \times 1 \mu \mathrm{m}$. No pin holes were observed in the micrographs, indicating successful deposition of compact films. As seen in Figure 4, the root mean square roughness (RMS) of the as-deposited films is about $2.5 \mathrm{~nm}$, which is in good agreement with that reported by Yan et al. [30]. The grain size of the annealed $\mathrm{ZnO}: \mathrm{Zr}$ films slightly decreases, as expected, before significantly increasing again at $850{ }^{\circ} \mathrm{C}$. It can be observed in Figure 3 that the grain size parallel to the surface is getting smaller, while the grain size vertical with the substrate is larger. The former reflects the (100) crystalline orientation, and the latter corresponds to the (002) crystalline orientation. Hence, the transformation of the prominent crystalline orientation from (100) to (002) is attributed to RTA process, which is consistent with the hypothesis obtained from the XRD patterns.

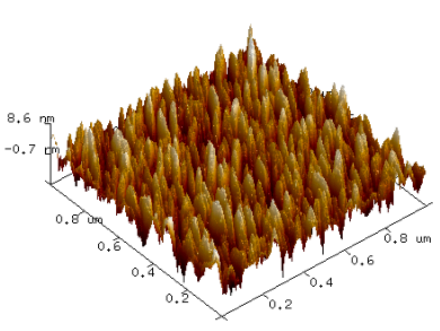

Height

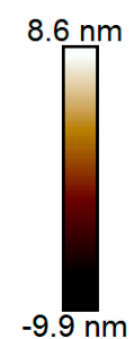

Height

(a)
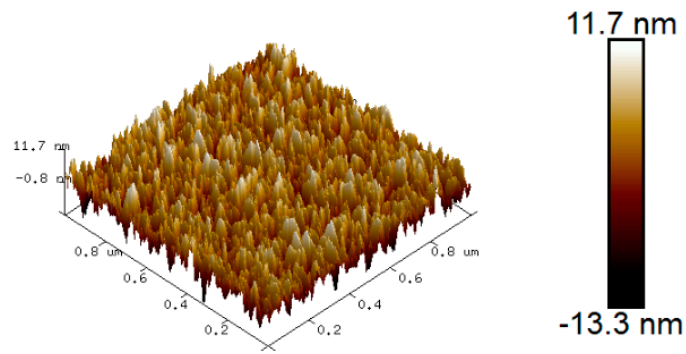


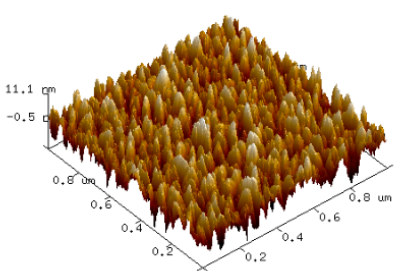

Height

(c)

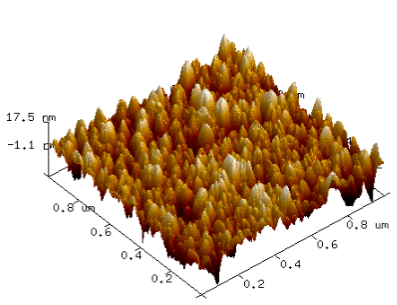

Height

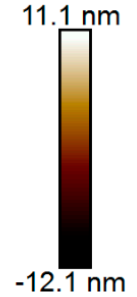

Height

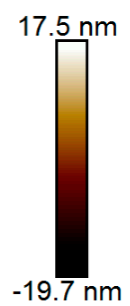

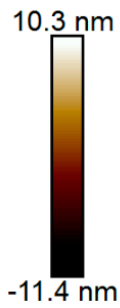

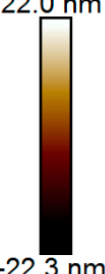

Height

(f)

Figure 3. Atomic force microscopy (AFM) images of $\mathrm{ZnO}: \mathrm{Zr}$ films grown on $\mathrm{Si}$ (100): (a) as-deposited; (b) $350{ }^{\circ} \mathrm{C}$; (c) $550{ }^{\circ} \mathrm{C}$; (d) $750{ }^{\circ} \mathrm{C}$; (e) $850{ }^{\circ} \mathrm{C}$; and (f) $950{ }^{\circ} \mathrm{C}$.

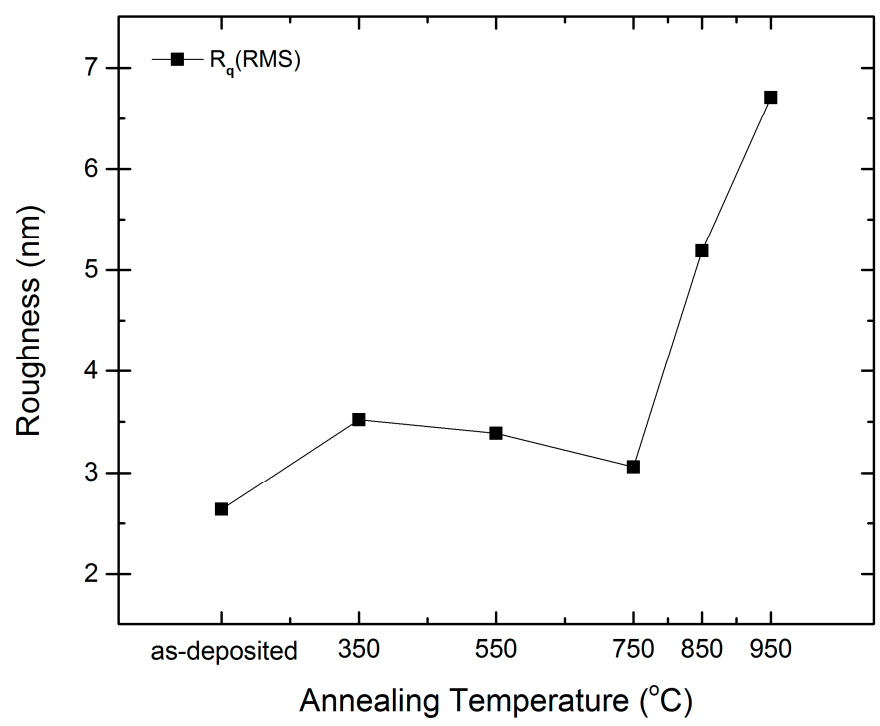

Figure 4. Surface roughness of the as-deposited and annealed $\mathrm{ZnO}: \mathrm{Zr}$ thin films grown on Si (100).

\subsection{Optical Properties}

Since the $\mathrm{ZnO}: \mathrm{Zr}$ film-coated glass is expected to be used as substrate for thin film solar cell fabrication, it is necessary to investigate the optical properties of $\mathrm{ZnO}: \mathrm{Zr}$ films under various RTA treatments. Figure 5 shows the optical transmittance in the wavelength region $350-800 \mathrm{~nm}$ of as-deposited and annealed $\mathrm{ZnO}: \mathrm{Zr}$ films. It is clear that the films show an average transmittance of over $92 \%$ in the visible wavelength. Also, it is important to note that with the increase of the annealing temperature, the edge of the transmission spectrum was red-shifted. The optical band gap $\left(E_{g}\right)$ was determined by extrapolation of the plot of $\alpha^{2}$ versus $h v$ [31]. 


$$
a(h v)=A\left(h v-E_{g}\right)^{n}
$$

where $\alpha$ is the absorption coefficient, $\mathrm{A}$ is a constant, $h v$ is the photon energy, $E_{g}$ is the optical band gap, and $n=1 / 2$ for direct band gap material. Figure 6 shows the optical band gap of the $\mathrm{ZnO} Z \mathrm{Zr}$ films under various RTA treatments. The band gap of the as-deposited $\mathrm{ZnO}: \mathrm{Zr}$ film is $3.31 \mathrm{eV}$, in agreement with the $3.30 \mathrm{eV}$ reported by Lin et al. [24]. The band gap keeps almost constant up to $550{ }^{\circ} \mathrm{C}$, then, it decreases to $3.245 \mathrm{eV}$ after the $950{ }^{\circ} \mathrm{C}$ treatment. The band gap narrowing effect (EBGN) is believed to be a result of many body effects, and is expressed as [25]:

$$
E_{B G N}=\frac{e^{2}}{2 \pi \varepsilon_{0} \varepsilon_{r}}\left(\frac{3}{\pi} n\right)^{\frac{1}{3}}
$$

where $\varepsilon_{0}$ is permittivity of vacuum, $\varepsilon_{r}$ is relative permittivity, and $n$ is the carrier concentration. The optical band gap is proportional to $(n)^{\frac{1}{3}}$. In Figure 6, the optical band gap decreases with the increase of the RTA temperature. Therefore, it is expected that carrier concentration will decrease when the annealing temperature is increasing.

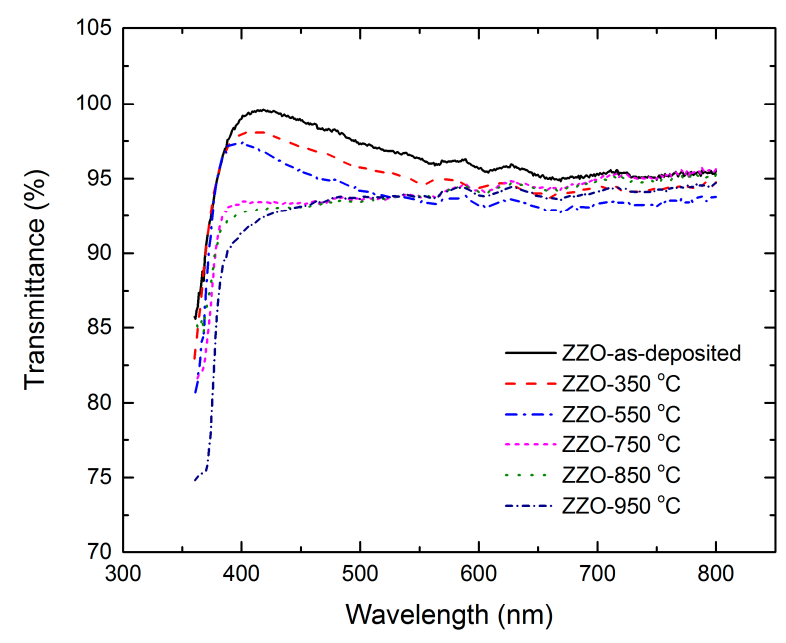

Figure 5. Optical transmittance as a function of wavelength for as-deposited and annealed ZnO:Zr films.

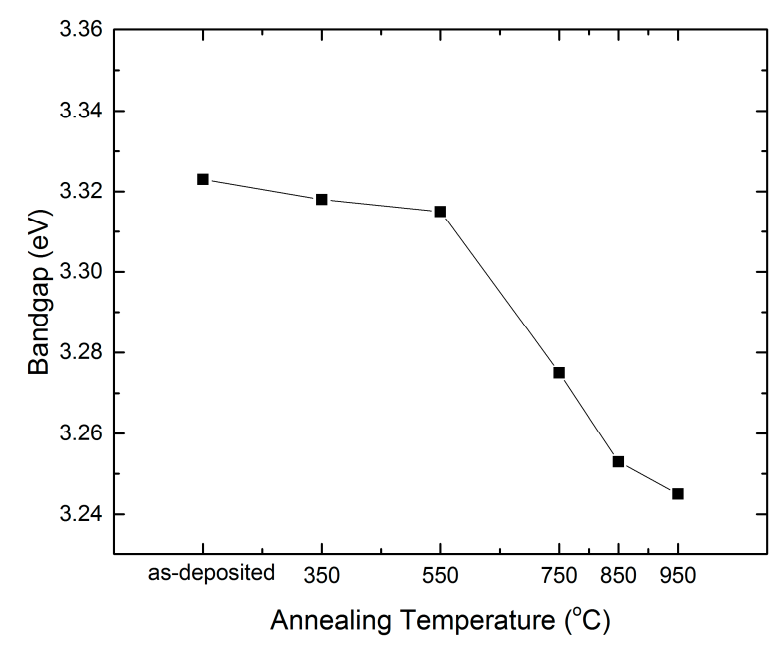

Figure 6. Optical band gap (Eg) of $\mathrm{ZnO}: \mathrm{Zr}$ thin films at various annealing temperatures. 


\subsection{Electrical Properties}

The electrical properties of the $\mathrm{ZnO}: \mathrm{Zr}$ films were characterized by Hall measurements using the van der Pauw configuration at room temperature. The change of electrical properties with the annealing temperature is illustrated in Figure 7. The resistivity keeps almost constant at annealing temperatures up to $550{ }^{\circ} \mathrm{C}$, then increases sharply from $1.27 \times 10^{-3}$ to $0.97 \times 10^{-1} \mathrm{ohm} \cdot \mathrm{cm}$ due to the rapid decrease of the carrier concentration and Hall mobility. Finally, it becomes an insulator after the $950{ }^{\circ} \mathrm{C}$ treatment. For the $\mathrm{ZnO}: \mathrm{Zr}$ films, carriers come from oxygen vacancies, $\mathrm{Zn}$ ions on interstitial lattice sites, and the substitution of $\mathrm{Zr}^{4+}$ on the $\mathrm{Zn}^{2+}$ site. It is reported that there are far fewer oxygen vacancies in the doped films than those in the undoped film [27]. Hence, the carrier concentration is mainly attributed to the $\mathrm{Zr}^{4+}$ doping. As previously mentioned, a diffusion of $\mathrm{Zr}^{4+}$ interstitials to the non-crystalline region in the grain boundary results in a decrease of carrier concentration. This phenomenon is also predicted from the band gap narrowing equation. An alternative explanation could be zinc evaporation during the annealing process leading to the decrease in carrier concentration. The mobility of the as-deposited films is $7.8 \mathrm{~cm}^{2} \cdot \mathrm{V}^{-1} \cdot \mathrm{S}^{-1}$, and it rises to $15.7 \mathrm{~cm}^{2} \cdot \mathrm{V}^{-1} \cdot \mathrm{S}^{-1}$ after the $550{ }^{\circ} \mathrm{C}$ RTA treatment. Then the mobility decreases dramatically to $1.6 \mathrm{~cm}^{2} \cdot \mathrm{V}^{-1} \cdot \mathrm{S}^{-1}$ at $850{ }^{\circ} \mathrm{C}$. As known, grain boundary scattering and ionized impurity scattering affect the mobility of the film. The resultant mobility follows the equation [17]:

$$
\frac{1}{\mu}=\frac{1}{\mu_{G B}}+\frac{1}{\mu_{I S}}
$$

where $\mu$ is the resultant mobility, $\mu_{G B}$ is the grain boundary scattering affected mobility, and $\mu_{I S}$ is the ionized impurity scattering affected mobility. The initial increase of the Hall mobility indicates that the grain growth is dominant over other factors. When the annealing temperature increases above $550{ }^{\circ} \mathrm{C}$, the Hall mobility decreases due to the increase of grain boundary scattering.

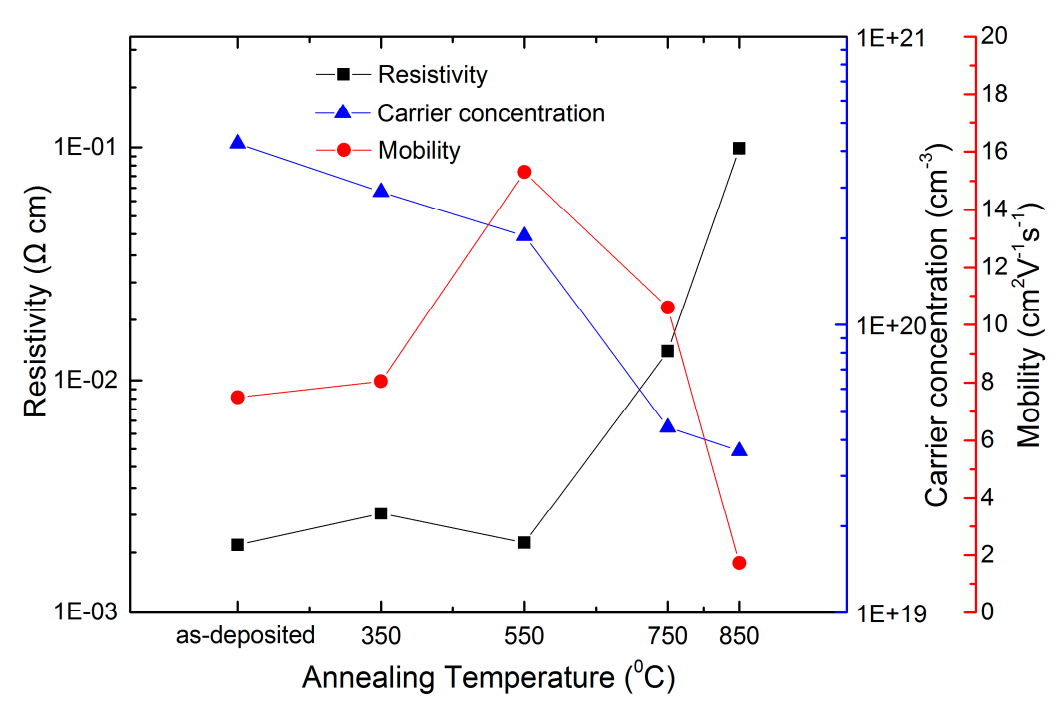

Figure 7. The resistivity, carrier concentration, and mobility of the $\mathrm{ZnO}: \mathrm{Zr}$ films as a function of annealing temperature.

\section{Materials and Methods}

Thin ZnO:Zr films were grown by an MNT F-200 system on quartz glass and virgin test grade $\mathrm{Si}$ (100) substrate, respectively. The optical properties and electrical properties of $\mathrm{ZnO}: \mathrm{Zr}$ films were investigated on the quartz glass sample, while $\mathrm{ZnO}: \mathrm{Zr}$ films on silicon substrate were used to characterize the thin film morphology. 
The substrates were firstly ultrasonically cleaned in isopropanol, acetone, alcohol, and deionized (DI) water for $10 \mathrm{~min}$ each. Then, each substrate was dried using high purity nitrogen. Diethyl-zinc (DEZn) and tetrakis-ethylmethylamino zirconium (TEMAZ) were used as the $\mathrm{Zn}$ and Zr sources, respectively, and DI water acted as an oxidizing agent. These precursors and an oxygen source were alternately introduced into the growth chamber with high purity nitrogen gas, which was used as the carrier gas and purging gas at a flow rate of $20 \mathrm{sccm}$. Typical ALD deposition sequences were DEZn (20 ms) $/ \mathrm{N}_{2}$ purge $(20 \mathrm{~s}) / \mathrm{H}_{2} \mathrm{O}(20 \mathrm{~ms}) / \mathrm{N}_{2}$ purge $(20 \mathrm{~s})$ and (TEMAZ (150 ms) $/ \mathrm{N}_{2}$ purge $(25 \mathrm{~s}) / \mathrm{H}_{2} \mathrm{O}(20 \mathrm{~ms}) / \mathrm{N}_{2}$ purge $(25 \mathrm{~s})$ for the growth of $\mathrm{ZnO}$ and $\mathrm{ZrO}_{2}$ films, respectively. The sandwich structural $\mathrm{ZnO}: \mathrm{Zr}$ films were obtained by repeating $\mathrm{N}$ cycles of $\mathrm{DEZn} / \mathrm{H}_{2} \mathrm{O}$ followed by one cycle of TEMAZ $/ \mathrm{H}_{2} \mathrm{O}$, then $\mathrm{M}$ cycles of DEZn $/ \mathrm{H}_{2} \mathrm{O}$ to get access to the desired doping concentration, as shown in Figure 8. The temperature for depositing the $\mathrm{ZnO}: \mathrm{Zr}$ films was maintained at $200^{\circ} \mathrm{C}$. The thicknesses of the films were measured by ellipsometer and were in the range of $94-95 \mathrm{~nm}$. The prepared $\mathrm{ZnO}: \mathrm{Zr}$ films were subjected to RTA (RTP-600XP, Modular Process Technology Corp., San Jose, CA, USA) treatment in the temperature range of $350-950{ }^{\circ} \mathrm{C}$ (with $200{ }^{\circ} \mathrm{C}$ as a step) in a high purity nitrogen atmosphere for $3 \mathrm{~min}$. Meanwhile, RTA treatment at $850^{\circ} \mathrm{C}$ also carried out as the resistivity increased rapidly during $750-950^{\circ} \mathrm{C}$.

The structural and crystallinity characterizations of the prepared samples were performed by an X-ray diffraction (XRD) system (D8 Advance, Bruker, Billerica, MA, USA) using Cu K $\alpha$ (40 kV and $40 \mathrm{~mA}, \lambda=1.54056 \AA$ ) on the range from $20^{\circ}$ to $80^{\circ}$ at 2 theta scale. The morphology were further characterized by AFM (Multimode 8, Bruker, Billerica, MA, USA). The optical properties of the annealing films were investigated using a UV-vis spectrometer (Cary 300, Agilent, Santa Clara, CA, USA). Electrical properties such as resistivity, carrier concentration, and mobility were measured by a Hall automatic measuring system (Accent HL6600PC, Midview City, Singapore) using the van der Pauw method. The contacts of the Hall measurement system were indium.

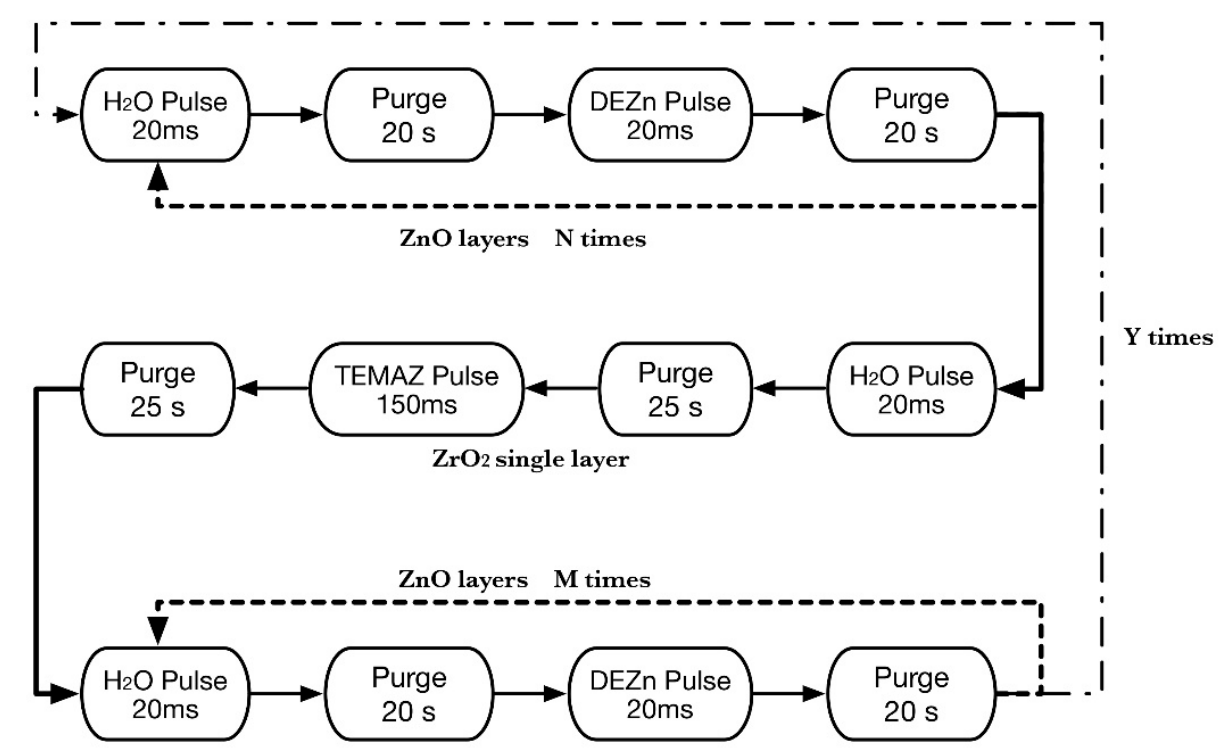

Figure 8. Schematic of the atomic layer deposition (ALD) deposition sequence used to deposit $\mathrm{ZnO} \mathrm{Zr}$ thin films.

\section{Conclusions}

In conclusion, the structural, optical, and electrical properties of the ALD-grown ZnO:Zr films treated with various annealing temperatures have been examined. The XRD results show that the grain size increases at low annealing temperatures and decreases due to the crystal disorder caused by zirconium dioxide segregation. The AFM indicates that the RMS increases slightly when the annealing temperature is lower than $750^{\circ} \mathrm{C}$. Then, it increases rapidly at higher annealing temperatures. 
The UV-vis spectrum shows that the films have good average transmittance of over $92 \%$ in visible wavelength and the optical band gap of the films show red-shift with increases of the annealing temperature. The Hall measurement shows that the resistivity increases slightly before $550{ }^{\circ} \mathrm{C}$ due to the decrease of carrier concentration and the increase of the mobility. Then, all three parameters decrease rapidly at higher annealing temperature. It is demonstrated that $\mathrm{ZnO}: \mathrm{Zr}$ films show good properties when treated in the temperature range between 350 and $550{ }^{\circ} \mathrm{C}$.

Acknowledgments: This research was funded in part from the National Natural and Science Foundation of China under the grant No. 11375146 and the platform promotion for Suzhou Municipal Key Lab "New Energy and Environmental Protection Techniques".

Author Contributions: Jingjin Wu extracted the data and drafted the manuscript. Jingjin Wu, Yinchao Zhao and Qifeng Lu prepared the samples. Qian Zhang performed the AFM and Yongming Zhao performed Hall Measurement. Ce Zhou Zhao monitored and led the whole research project. Li Yang and Jeremy S. Smith participated in the discussions. All of the authors read and approved the final manuscript and this submission.

Conflicts of Interest: The authors declare no conflict of interest.

\section{References}

1. Jain, A.; Sagar, P.; Mehra, R.M. Band gap widening and narrowing in moderately and heavily doped n-ZnO films. Solid State Electron. 2006, 50, 1420-1424. [CrossRef]

2. Banerjee, P.; Lee, W.-J.; Bae, K.-R.; Lee, S.B.; Rubloff, G.W. Structural, electrical, and optical properties of atomic layer deposition Al-doped ZnO films. J. Appl. Phys. 2010, 108, 043504. [CrossRef]

3. Dasgupta, N.P.; Neubert, S.; Lee, W.; Trejo, O.; Lee, J.-R.; Prinz, F.B. Atomic Layer Deposition of Al-doped ZnO Films: Effect of Grain Orientation on Conductivity. Chem. Mater. 2010, 22, 4769-4775. [CrossRef]

4. Lee, D.-J.; Kim, H.-M.; Kwon, J.-Y.; Choi, H.; Kim, S.-H.; Kim, K.-B. Structural and Electrical Properties of Atomic Layer Deposited Al-Doped ZnO Films. Adv. Funct. Mater. 2011, 21, 448-455. [CrossRef]

5. Saito, K.; Hiratsuka, Y.; Omata, A.; Makino, H.; Kishimoto, S.; Yamamoto, T.; Horiuchi, N.; Hirayama, H. Atomic layer deposition and characterization of Ga-doped ZnO thin films. Superlattices Microstruct. 2007, 42, 172-175. [CrossRef]

6. Chalker, P.R.; Marshall, P.A.; Romani, S.; Roberts, J.W.; Irvine, S.J.C.; Lamb, D.A.; Clayton, A.J.; Williams, P.A. Atomic layer deposition of Ga-doped $\mathrm{ZnO}$ transparent conducting oxide substrates for CdTe-based photovoltaics. J. Vac. Sci. Technol. A 2013, 31, 01A120. [CrossRef]

7. Lee, D.-H.; Kim, K.; Chun, Y.S.; Kim, S.; Lee, S.Y. Substitution mechanism of Ga for Zn site depending on deposition temperature for transparent conducting oxides. Curr. Appl. Phys. 2012, 12, 1586-1590. [CrossRef]

8. Liu, W.-S.; Wu, S.-Y.; Hung, C.-Y.; Tseng, C.-H.; Chang, Y.-L. Improving the optoelectronic properties of gallium $\mathrm{ZnO}$ transparent conductive thin films through titanium doping. J. Alloys Compd. 2014, 616, $268-274$. [CrossRef]

9. Faye, S.; Steinhauser, J.; Oliveira, N.; Vallat-Sauvain, E.; Ballif, C. Opto-electronic properties of rough LP-CVD ZnO: B for use as TCO in thin-film silicon solar cells. Thin Solid Films 2007, 515, 8558-8561. [CrossRef]

10. Fay, S.; Steinhauser, J.; Nicolay, S.; Ballif, C. Polycrystalline ZnO: B grown by LPCVD as TCO for thin film silicon solar cells. Thin Solid Films 2010, 518, 2961-2966. [CrossRef]

11. Lim, S.Y.; Brahma, S.; Liu, C.-P.; Wang, R.-C.; Huang, J.-L. Effect of indium concentration on luminescence and electrical properties of indium doped ZnO nanowires. Thin Solid Films 2013, 549, 165-171. [CrossRef]

12. Illiberi, A.; Scherpenborg, R.; Roozeboom, F.; Poodt, P. Atmospheric Spatial Atomic Layer Deposition of In-Doped ZnO. ECS J. Solid State Sci. Technol. 2014, 3, P111-P114. [CrossRef]

13. Chalker, P.R.; Marshall, P.A.; King, P.J.; Dawson, K.; Romani, S.; Williams, P.A.; Ridealgh, J.; Rosseinsky, M.J. Atomic layer deposition of germanium-doped zinc oxide films with tuneable ultraviolet emission. J. Mater. Chem. 2012, 22, 12824-12829. [CrossRef]

14. Ye, Z.-Y.; Lu, H.-L.; Geng, Y.; Gu, Y.-Z.; Xie, Z.-Y.; Zhang, Y.; Sun, Q.-Q.; Ding, S.-J.; Zhang, D.W. Structural, electrical, and optical properties of Ti-doped $\mathrm{ZnO}$ films fabricated by atomic layer deposition. Nanoscale Res. Lett. 2013, 8, 1-6. [CrossRef] [PubMed]

15. Lv, M.; Xiu, X.W.; Pang, Z.Y.; Dai, Y.; Han, S.H. Transparent conducting zirconium-doped zinc oxide films prepared by rf magnetron sputtering. Appl. Surf. Sci. 2005, 252, 2006-2011. [CrossRef] 
16. Lv, M.; Xiu, X.W.; Pang, Z.Y.; Dai, Y.; Han, S.H. Influence of the deposition pressure on the properties of transparent conducting zirconium-doped zinc oxide films prepared by RF magnetron sputtering. Appl. Surf. Sci. 2006, 252, 5687-5692. [CrossRef]

17. Lv, M.; Xiu, X.; Pang, Z.; Dai, Y.; Ye, L.; Cheng, C.; Han, S. Structural, electrical and optical properties of zirconium-doped zinc oxide films prepared by radio frequency magnetron sputtering. Thin Solid Films 2008, 516, 2017-2021. [CrossRef]

18. Zhang, H.; Lei, C.L.; Liu, H.; Yuan, C. Low-temperature deposition of transparent conducting ZnO:Zr films on PET substrates by DC magnetron sputtering. Appl. Surf. Sci. 2009, 255, 6054-6056. [CrossRef]

19. Bahedi, K.; Addou, M.; El Jouad, M.; Bayoud, S.; Sofiani, Z. Effects of deposition temperature on the surface roughness and the nonlinear optical susceptibility of sprayed deposited ZnO:Zr thin films. Appl. Surf. Sci. 2009, 255, 9054-9057. [CrossRef]

20. Gokulakrishnan, V.; Parthiban, S.; Jeganathan, K.; Ramamurthi, K. Investigation on the effect of Zr doping in ZnO thin films by spray pyrolysis. Appl. Surf. Sci. 2011, 257, 9068-9072. [CrossRef]

21. Kim, H.; Horwitz, J.S.; Kim, W.H.; Makinen, A.J.; Kafafi, Z.H.; Chrisey, D.B. Doped ZnO thin films as anode materials for organic light-emitting diodes. Thin Solid Films 2002, 420, 539-543. [CrossRef]

22. Kim, H.; Horwitz, J.S.; Kim, W.H.; Qadri, S.B.; Kafafi, Z.H. Anode material based on Zr-doped ZnO thin films for organic light-emitting diodes. Appl. Phys. Lett. 2003, 83, 3809-3811. [CrossRef]

23. Paul, G.K.; Bandyopadhyay, S.; Sen, S.K.; Sen, S. Structural, optical and electrical studies on sol-gel deposited Zr doped ZnO films. Mater. Chem. Phys. 2003, 79, 71-75. [CrossRef]

24. Lin, M.-C.; Chang, Y.-J.; Chen, M.-J.; Chu, C.-J. Characteristics of Zr-Doped ZnO Thin Films Grown by Atomic Layer Deposition. J. Electrochem. Soc. 2011, 158, D395-D398. [CrossRef]

25. Herodotou, S.; Treharne, R.E.; Durose, K.; Tatlock, G.J.; Potter, R.J. Article The Effects of Zr Doping on the Optical, Electrical and Microstructural Properties of Thin ZnO Films Deposited by Atomic Layer Deposition. Materials 2015, 8, 7230-7240. [CrossRef]

26. Zhang, J.; Gao, D.; Yang, G.; Zhang, J.; Shi, Z.; Zhang, Z.; Zhu, Z.; Xue, D. Synthesis and magnetic properties of Zr doped ZnO Nanoparticles. Nanoscale Res. Lett. 2011, 6, 587. [CrossRef] [PubMed]

27. Zhu, S.-B.; Geng, Y.; Lu, H.-L.; Zhang, Y.; Sun, Q.-Q.; Ding, S.-J.; Zhang, D.W. Effects of rapid thermal annealing on Hf-doped ZnO films grown by atomic layer deposition. J. Alloys Compd. 2013, 577, 340-344. [CrossRef]

28. Qadria, S.B.; Khanc, H.K.H.R.; Piquea, A.; Horwitza, J.S.; Chriseya, D.; Kima, W.J.; Skelton, E.F. Transparent conducting films of $\mathrm{In}_{2} \mathrm{O}_{3}-\mathrm{ZrO}_{2}, \mathrm{SnO} 2-\mathrm{ZrO}_{2}$ and $\mathrm{ZnO}-\mathrm{ZrO}_{2}$. Thin Solid Films 2000, 377, 750-754. [CrossRef]

29. Pung, S.-Y.; Choy, K.-L.; Hou, X.; Shan, C. Preferential growth of ZnO thin films by the atomic layer deposition technique. Nanotechnology 2008, 19, 435609. [CrossRef] [PubMed]

30. Yen, C.Y.; Jian, S.R.; Chen, G.J.; Lin, C.M.; Lee, H.Y.; Ke, W.C.; Liao, Y.Y.; Yang, P.F.; Wang, C.T.; Lai, Y.S.; et al. Influence of annealing temperature on the structural, optical and mechanical properties of ALD-derived ZnO thin films. Appl. Surf. Sci. 2011, 257, 7900-7905. [CrossRef]

31. Tsay, C.-Y.; Fan, K.-S. Optimization of Zr-doped ZnO thin films prepared by sol-gel method. Mater. Trans. 2008, 49, 1900-1904. [CrossRef]

(C) 2016 by the authors; licensee MDPI, Basel, Switzerland. This article is an open access article distributed under the terms and conditions of the Creative Commons Attribution (CC-BY) license (http://creativecommons.org/licenses/by/4.0/). 